\title{
Carbon sequestration in mature rubber (Hevea brasiliensis Muell. Arg.) plantations with genotypic comparison
}

\author{
E S Munasinghe*, V H L Rodrigo* and P K W Karunathilake* \\ *Rubber Research Institute of Sri Lanka, Dartonfield, Agalawatta, Sri Lanka
}

Received 18 November 2011; Accepted 2 January 2012

\begin{abstract}
Forests play a vital role in regulating the greenhouse gases, particularly the level of atmospheric $\mathrm{CO}_{2}$; hence planting forests has been identified as one of the main options available to mitigate the effects of climate change. Rubber (Hevea brasiliensis), being a multipurpose tree which provides an economically viable (in terms of both latex and timber production) and socially acceptable system, can be effectively used in participatory tree planting programmes. Although the availability of carbon in rubber trees has been assessed before, the potential capacity of sequestering atmospheric $\mathrm{CO}_{2}$ in mature rubber trees has not been quantified. Therefore the present study was geared towards this whilst characterizing the genotypic differences in $\mathrm{CO}_{2}$ sequestration. Two promising genotypes viz. RRIC121 and RRIC100, were selected for the study. $\mathrm{CO}_{2}$ assimilation rates of rubber leaves in three canopy strata under varying light levels were measured and parameters of photosynthetic light response curves (LRC) were estimated. Leaf area distribution and light attenuation within the canopy were also measured. With previous weather records on incident light, its availability at different canopy levels was estimated using existing ecophysiological models and then the photosynthetic rates at canopy level were estimated. Maximum rate of photosynthesis and quantum yield (photosynthetic efficiency) decreased with the increase in depth of the canopy whilst it was vice versa for the convexity of light response curve. In general, parameters of LRC were superior in RRIC 121 to RRIC 100. Irrespective of the clone, a greater proportion of leaves was found in the top than in the lowest stratum. Leaf area index in RRIC 121 was greater than RRIC 100 with values of 5.88 and 3.47, respectively. Light extinction coefficient was less in RRIC 121 allowing more light to penetrate through the canopy than in RRIC 100. The capability of sequestering atmospheric $\mathrm{CO}_{2}$ was greater in RRIC 121 than that in RRIC 100 with annual rates of 117 and 45 $M T h a^{-1}$, respectively. On average, mature rubber is capable of sequestering $81 M T$ of $\mathrm{CO}_{2}$ per hectare annually and, within the 24 years of mature phase, 1,296 $\mathrm{MT}$ of $\mathrm{CO}_{2}$ would be sequestered in a hectare of rubber.
\end{abstract}

Key words: climate change, photosynthesis, rubber 
E S Munasinghe et al.

\section{Introduction}

The global climate has been changing with the enhanced greenhouse effect; hence identification of effective measures to combat the adverse impacts of climate change is of uttermost importance. Options available to mitigate climate change impacts could be categorized into two; namely reducing emissions of greenhouse gasses into the atmosphere and increasing the capacity of present sinks to absorb greenhouse gasses thereby reducing their accumulation in the atmosphere (Anon, 2001; Anon, 2002a). Tree crops play a key role in mitigation of climate change by long-term fixation of atmospheric carbon dioxide $\left(\mathrm{CO}_{2}\right)$ through photosynthesis. In this context, cultivation of rubber (Hevea brasiliensis) could also be considered as a mitigation option for climate change (Anon, 2002b) whilst obtaining its direct benefits such as latex, timber and firewood.

Photosynthesis is the primary process responsible for biomass accumulation of plants as well as sequestering atmospheric $\mathrm{CO}_{2}$. Therefore, $\mathrm{CO}_{2}$ sequestration capacity of crops is determined through net $\mathrm{CO}_{2}$ assimilation measured by the gas exchange techniques at the field level. $\mathrm{CO}_{2}$ assimilation rate of rubber has been assessed previously by Samsuddin and Impens (1979), Nugawela (1989) and Seneviratne et al. (2003). However, those have mainly been confined to leaf level measurement in field grown or potted juvenile plants due to the fact that those studies were designed for different purposes. For instance, Nugawela (1989) assessed the photosynthetic characteristics of juvenile plants to examine the association of photosynthetic characteristics with yield potentials of mature plants. It is not easy to extrapolate the leaf level photosynthetic rate to the crop level without proper understanding of the canopy architecture (i.e. how leaves orient in the canopy) and the influence of varying climatic parameters. A mature rubber crop provides a closed canopy allowing little light to penetrate (Ibrahim, 1991) whilst small plants behave like discrete units exposing most of their leaves to incoming radiation. Also, tapping of rubber trees for latex could influence the carbon fixing capacity due to its effect on carbon 'sink'. In addition to its potential for aforestation/reforestation programmes, under Clean Development Mechanism, negotiations have come forward to remunerate the sequestration of existing forests under Reduce Emission from Deforestation and forest Degradation (REDD). As a readiness activity for REDD, the present study was done to quantify the $\mathrm{CO}_{2}$ sequestration capacity of rubber giving due consideration to canopy dynamics with respect to light attenuation and variation in photosynthetic capacity at different levels and also with a proper account of environmental changes. Growth, yield and $\mathrm{CO}_{2}$ sequestration capacity of rubber could be vary with genotype. Therefore, this study also 
focused on investigating possible genotypic variation in $\mathrm{CO}_{2}$ sequestration in rubber.

\section{Methodology \\ Experimental site and plant material} The experiment was conducted in the Dartonfield estate of the Rubber Research Institute of Sri Lanka situated at Agalawatte (latitudes: $6^{0} 32^{\prime} \mathrm{N}$ and longitudes: $80^{\circ} 09^{\prime}$ E) within the agroclimatic zone WL1 (Anon, 1988) in 2004. Although, rubber trees come to the harvestable stage by $c a$. 6 years, there is a gradual increase in yield up to ca. 12-13 years after planting. Therefore, two genotypes of rubber, i.e. RRIC 100 and RRIC 121, planted in 1991 under same field conditions with respect to soil type and topography, were selected for the study.

\section{Assessments}

The assessment of carbon sequestration capacity of rubber trees was based on the measurements of leaf level photosynthesis, radiation attenuation through the rubber canopies as determined by leaf area distribution and canopy architecture and diurnal variation of incident radiation.

\section{Measurement of leaf level} photosynthesis and canopy architecture The canopy was divided into three strata of $4 \mathrm{~m}$ depth each. As trees were $c a .22$ $\mathrm{m}$ high, height distribution of strata was as top (22-18 m), middle (18-14 m) and low (14-10 m). Photosynthesis measurements were limited to three detached leaves in each stratum of each tree (IRGA, Model LI6400, Li Cor Ltd, USA). Measurements on both genotypes were repeated in five trees taken on five different days. Of each leaf, $\mathrm{CO}_{2}$ assimilation was measured at 10 different light levels (i.e. 30, 50, 75, 100, 150, 200, 300, 500, 1000, 1500 $\mu$ molm $^{-2} \mathrm{~s}^{-1}$ ) with the support of an artificial light source mounted on the leaf chamber of IRGA (6400-02B Red/Blue light source). For each leaf, the light response curve (LRC) was fitted with a function of non-rectangular hyperbola derived from a quadratic equation given below (see equation (1); Thornley and Johnson, 1990) and maximum rate of photosynthesis $\left(\mathrm{P}_{\max },\right)$, photosynthetic efficiency $(\alpha)$ and convexity of LRC $(\theta)$ were estimated using the software package "Photosyn Assistant" (Ver.1.1, Department of Biological Sciences, University of Essex, UK).

Equation 1: Quadratic equation used to fit the light response curve in photosynthesis (Thornley and Johnson, 1990).

$\mathrm{P}=\left\{\left[\left(\alpha^{*} \mathrm{I}\right)+\mathrm{P}_{\max }\right]-\left[\left(\alpha^{*} \mathrm{I}\right)+\mathrm{P}_{\max }\right]^{2}-\right.$ $\left.\left.\left(4 * \theta^{*} \alpha *{ }^{*} \mathrm{P}_{\max }\right)\right]^{5}\right\} / 2 * \theta$

Where,

$\mathrm{P}$ - Instantaneous rate of photosynthesis $\left(\mu \mathrm{mol} \mathrm{m} \mathrm{m}^{-2}\right)$

$\mathrm{P}_{\text {max }}$ - Maximum rate of photosynthesis (described by the value of $\mathrm{CO}_{2}$ assimilation rate at saturating irradiance, i.e. the upper asymptote of the LRC). 
E S Munasinghe et al.

$\alpha$ - Photosynthetic efficiency (determined by the initial slope of the LRC where incident irradiance

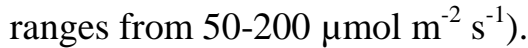

$\theta$ - Convexity of LRC

I - Level of irradiance

Light attenuation within the canopy depends on canopy architecture and is described by the Monsi-Saeki (1953) (Equation 2).

Equation 2: Monsi-Saeki equation describing the light attenuation within the canopy.

$\mathrm{I}=\mathrm{I}_{\mathrm{o}} \mathrm{e}^{-\mathrm{kL}(\mathrm{z})}$

Where,

$I_{o}$ - Incident irradiance at the top of the canopy

$\mathrm{k}$ - Extinction coefficient of the canopy

$\mathrm{L}$ - Leaf area index (LAI)

Measurements on Leaf area index (LAI) and light Extinction Coefficient were made as described below.

Determination of Leaf Area Index (LAI) Being deciduous, defoliation of rubber provided the facility of determining LAI by collecting fallen leaves. During defoliation, three rectangular litter traps $\left(20 \mathrm{~m}^{2}\right)$ were positioned randomly in the experimental field. The total leaflets accumulated in traps were collected from time to time up to the end of the defoliation period and the total area of the leaflets was measured using a leaf area meter (Model LI3000, Li Cor Ltd, USA). LAI was calculated as,

LAI= Area of the leaflets per litter trap $\left(\mathrm{m}^{2}\right) /$ Area of the litter trap $\left(\mathrm{m}^{2}\right)$
The proportion of LAI found in three strata of the canopy was estimated by physical counting using point quadrats inclined at an angle of $32.5^{\circ}$ (Nobel and Long, 1985). One end of a piece of twine was placed on the surface of the canopy and the other end was fixed at a random point on the ground at an angle of $32.5^{0}$ to the horizontal. The number of contacts the twine made with leaves of each stratum was counted. In order to determine the LAI per each stratum, LAI of the whole canopy was weighted with the ratio of contacts among canopy strata.

Determination of the light extinction coefficient

In order to determine the canopy light extinction coefficient, nine sets of irradiance measurements were taken in each clone using Ceptometer (Delta $\mathrm{T}$ Devices Ltd, UK). Each set comprised two measurements, one on top of the canopy, i.e. incident irradiance (Io), and the other at the bottom of the canopy, i.e. transmitted irradiance (I). Using these values and LAI measured for the whole canopy, the canopy extinction coefficient ' $\mathrm{k}$ ' was estimated for each genotype with equation (2).

Diurnal variation and accounting of cloud effect on incident solar radiation

In wet tropics, incident solar radiation on crop canopies depends largely on diurnal time course variation and presence of clouds during the daytime. In order to study the diurnal pattern of solar radiation, a typical sunny day and 
a dull day were selected and incident radiation was measured (Ceptometer Delta $\mathrm{T}$ Devices Ltd, UK) in five locations at each day time hour, i.e. from 0600 to $1800 \mathrm{~h}$. Then, the mean incident radiation at each day time hour for sunny and dull conditions was calculated.

Thereafter, light availability in each stratum of the rubber canopy at both sunny and dull conditions was established based on the information on the stratified LAI distribution and $\mathrm{k}$ using the Monsi-Saeki equation in each genotype (Equation 2).

Diurnal variation in canopy photosynthesis $(P c)$

Knowing the light availability and other photosynthetic parameters, mean net photosynthetic rates at leaf level of each stratum at both sunny and dull conditions were determined using equation 1 for a given stratum and day time hour. Integration of values in the three strata gave the canopy photosynthetic rate.

Estimation of the amount of $\mathrm{CO}_{2}$ sequestered by rubber crop

Values of canopy photosynthetic rate (Pc) obtained at each day time hour were used to estimate the daily integral of $\mathrm{CO}_{2}$ sequestered under sunny and dull conditions. At each stratum and at each day time hour, the mass of $\mathrm{CO}_{2}$ sequestered was estimated using the molecular weight of $\mathrm{CO}_{2}$ (44) and then expressed in terms of per hectare and per plant basis with the knowledge of ground area and tree density (i.e. 500 trees per hectare since no vacant trees were present around the rubber trees used for the measurements), respectively. Final value for the particular day time hour was obtained by totaling values of all three strata and then the value for the day was calculated through the integration all day time values.

In the estimation of potential monthly and annual integrals of $\mathrm{CO}_{2}$ sequestered, possibility to be sunny and dull light conditions at each time point of the day was considered. Total number of sunny and dull hours in each calendar month was obtained from previous studies (Iqbal, 2003). Then, the amount of $\mathrm{CO}_{2}$ sequestered in each month was estimated by matrix multiplication of total sunny and dull hours of the month and the diurnal distribution $\mathrm{CO}_{2}$ sequestered under sunny and dull conditions. The value for the year was derived with the summation of monthly values. However, the period when defoliation and refoliation occurred in rubber in the particular year of study (i.e. December to February), was ignored in this estimation as the $\mathrm{CO}_{2}$ sequestration is marginal during this period.

\section{Results}

Photosynthetic parameters of mature rubber trees

Estimated maximum rates of photosynthesis, $\mathrm{P}_{\max }$ for different canopy strata of genotypes RRIC 100 and RRIC 121 are shown in Figure 1. The 
E S Munasinghe et al.

variation of $\mathrm{P}_{\max }$ through the canopy was similar in both clones with the highest values being recorded in the top stratum and the lowest in the lowest stratum. However, in general, $\mathrm{P}_{\max }$ values of clone RRIC 121 was greater than those in clone RRIC 100 for all strata.

There was no clear difference in photosynthetic efficiency, $\alpha$ between different strata in both genotypes. However values recorded for RRIC 121 were greater with the mean values of 0.04 for RRIC 121 and 0.03 for RRIC 100 (Fig. 2).

Convexity of the LRC, $\theta$ for the genotypes RRIC 100 and RRIC 121 is given in Figure 3. In general, $\theta$ remained constant among the canopy strata. However, $\theta$ of clone RRIC 121

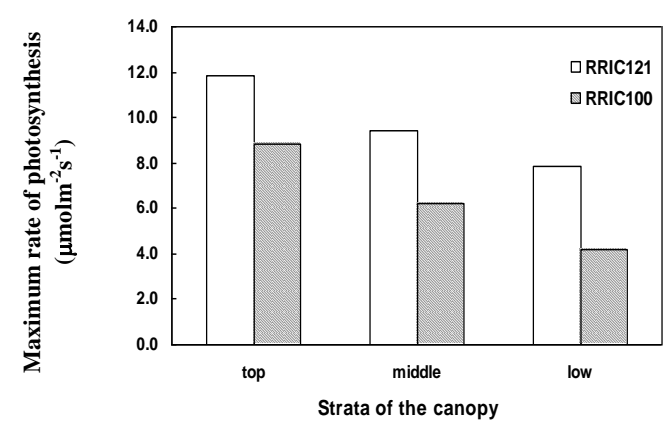

Fig. 1. Estimated maximum rate of photosynthesis, $\mathrm{P}_{\max }$ for the leaves at different canopy levels, i.e. top, middle and low strata of mature RRIC 100 and RRIC 121 genotypes was slightly greater than that of clone R0RIC 100 in all strata.

\section{Leaf area composition}

The LAI of genotype RRIC 121 was greater than that of RRIC 100 and the mean values for the whole canopy were 5.88 and 3.47, respectively. Both genotypes have shown a similar pattern of leaf distribution within the canopy. However, a greater proportion of leaf area index was found in top stratum with the lowest in the bottom stratum (Fig. 4).

The light extinction coefficient of the clone RRIC 121 was found to be less than that of RRIC 100 with the values 0.3 and 0.58 , respectively.

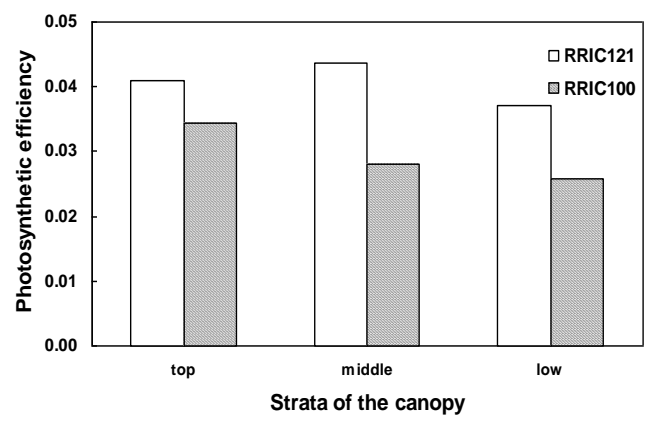

Fig. 2. Photosynthetic efficiency, $\alpha$ for the leaves at different canopy levels, i.e. top, middle and low strata of mature RRIC 100 and RRIC 121 genotypes 


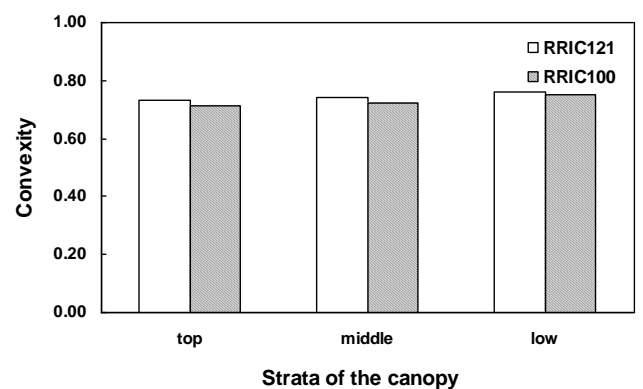

Fig. 3. Convexity, $\theta$ of light response curve at different canopy levels

Light availability and its attenuation through the rubber canopy

Diurnal variation of incident solar radiation between 0600 to 1800 hours for a sunny and a dull day is shown in Figure 5. Obviously, the amount of energy received on a sunny day was higher than that of a dull day with peak values recorded between 1000 to 1400

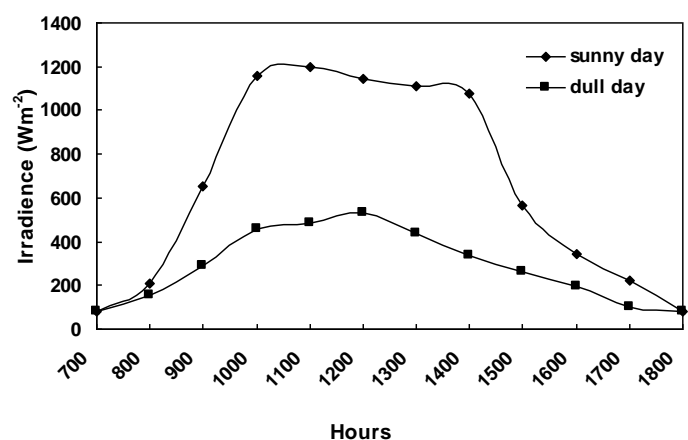

Fig. 5. Diurnal variation in the incident solar radiation on sunny and dull days

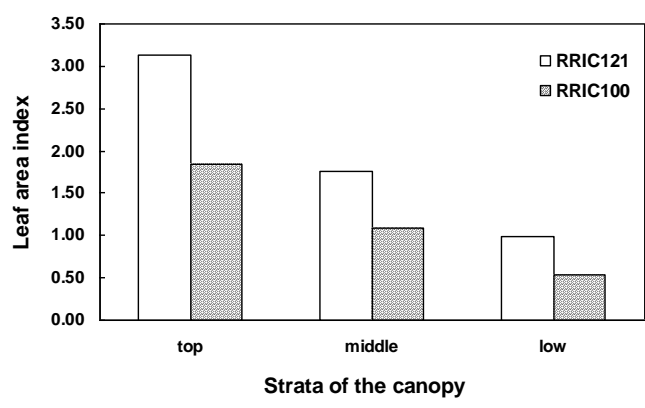

Fig. 4. Distribution of leaf area index, LAI with respect to different canopy levels

hours. In total, the energy received for a day varied between 7.8 to $3.4 \mathrm{kWm}^{-2}$.

The possibility of having a sunny condition during the mid hours of the day was greater than that in the morning or evening (Fig. 6). Also, the possibility of sunny conditions during the months of February, March and December was higher than in other months (Fig. 7).

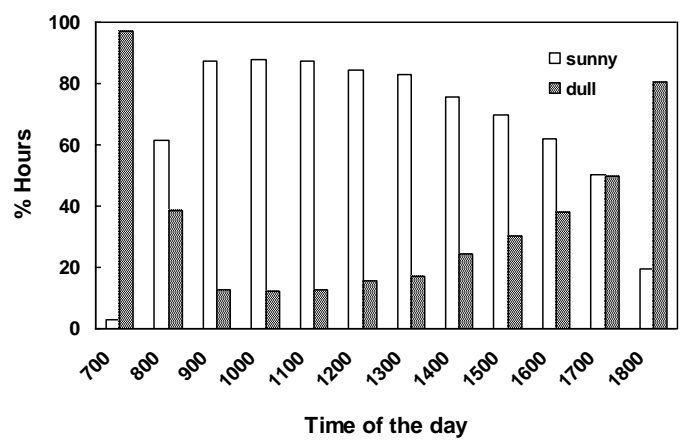

Fig. 6. Incidence of sunny and dull conditions during the cause of the day. Values are given as a percentage for a period of one year 
E S Munasinghe et al.

As shown by the light extinction coefficient, the amount of light transmitted through the crop canopy was greater in RRIC 121 with an additional $4 \%$ of light reaching the bottom of canopy when compared to RRIC 100 (Fig. 8). However, for both genotypes, light attenuation was very rapid during the top positions of the canopy and then light levels approached an asymptote, a steady level.

\section{Canopy photosynthesis rates of rubber}

In general, the rate of photosynthesis at the leaf level was higher in RRIC 121 than in RRIC 100. Also, photosynthetic rate in the upper stratum was greater than in other strata, particularly in RRIC 121 (Table 1). High photosynthetic rates of RRIC 121 was prominent even throughout the day (Fig. 9). Because of the availability of light, both genotypes showed high level of photosynthesis during the mid hours. Values at noon were $260 \%$ greater over those at 0600 -

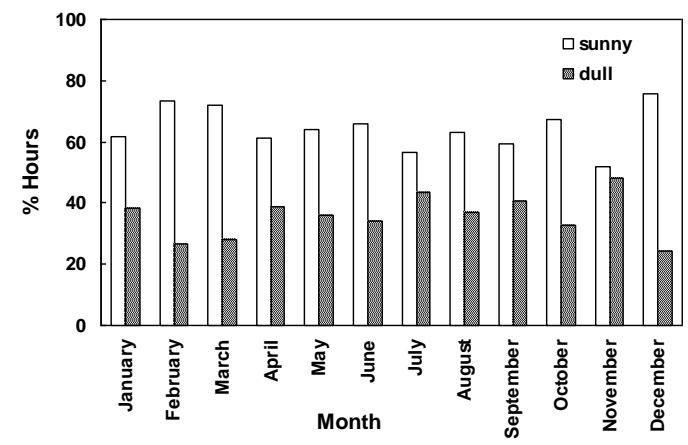

Fig. 7. Incidence of sunny and dull conditions in each calendar month. Values are given as a percentage for the particular month
0700 hours or $1700-1800$ hours (Fig. 9 \& 10). Nevertheless, there was an overall difference of $28 \%$ between the values recorded for sunny and dull conditions.

\section{Carbon sequestration of rubber}

The amount of $\mathrm{CO}_{2}$ sequestered on a sunny and a dull day was 31.7 and 25.6 $\mathrm{gm}^{-2}$, respectively on ground areas basis. Based on the number of sunny and dull conditions, the amount of $\mathrm{CO}_{2}$ sequestered in different calendar months is given in Table 2. The highest rate of $\mathrm{CO}_{2}$ sequestration was recorded in the month of March, whilst the lowest rate was recorded in November. However, the difference was only $0.68 \mathrm{MTha}^{-1}$. In all circumstances, the genotype RRIC 121 has outperformed RRIC 100. The annual rate of $\mathrm{CO}_{2}$ sequestered in the genotype RRIC 121 was $116 \mathrm{MTha}^{-1}$ and $160 \%$ greater than that of RRIC 100.

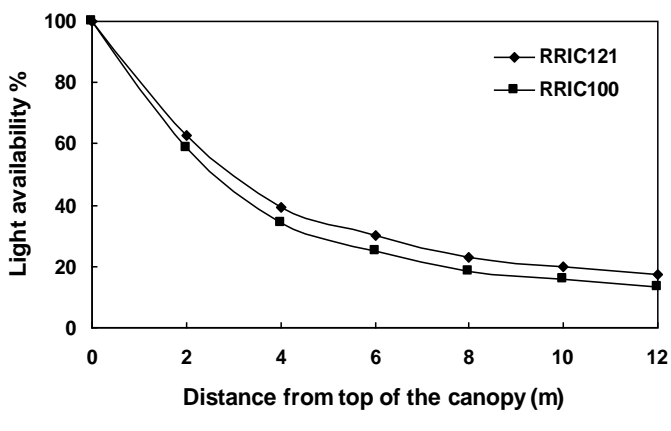

Fig. 8. Attenuation of light through the rubber canopy 
Carbon sequestration in mature rubber

Table 1. Mean photosynthetic rates $\left(P c-\mu \mathrm{molm}^{-2} \mathrm{~s}^{-1}\right)$ in different strata of the rubber canopy

\begin{tabular}{llccc}
\hline \multirow{2}{*}{ Clone } & \multirow{2}{*}{ Light condition of the day } & \multicolumn{3}{c}{ Canopy stratum } \\
\cline { 3 - 5 } & & Top & Middle & Bottom \\
\hline \multirow{2}{*}{ RRIC 121 } & sunny & 4.86 & 3.51 & 2.72 \\
& dull & 4.10 & 2.71 & 1.88 \\
\multirow{2}{*}{ RRIC 100 } & sunny & 3.43 & 2.05 & 1.45 \\
& dull & 2.91 & 1.49 & 1.01 \\
\hline
\end{tabular}

Table 2. Seasonal variation of $\mathrm{CO}_{2}$ sequestration of two genotypes of rubber

\begin{tabular}{lcc}
\hline Month & Amount of $\mathbf{C O}_{\mathbf{2}}$ sequestered $\left(\mathbf{M T h a}^{\mathbf{- 1}}\right)$ \\
\cline { 2 - 3 } & RRIC 121 & RRIC 100 \\
\hline March & 13.42 & 5.15 \\
April & 12.71 & 4.87 \\
May & 13.20 & 5.06 \\
June & 12.83 & 4.92 \\
July & 13.00 & 4.98 \\
August & 13.18 & 5.05 \\
September & 12.65 & 4.85 \\
October & 13.30 & 5.10 \\
November & 12.45 & 4.77 \\
\hline Total & $\mathbf{1 1 6 . 7 5}$ & $\mathbf{4 4 . 7 6}$ \\
\hline
\end{tabular}

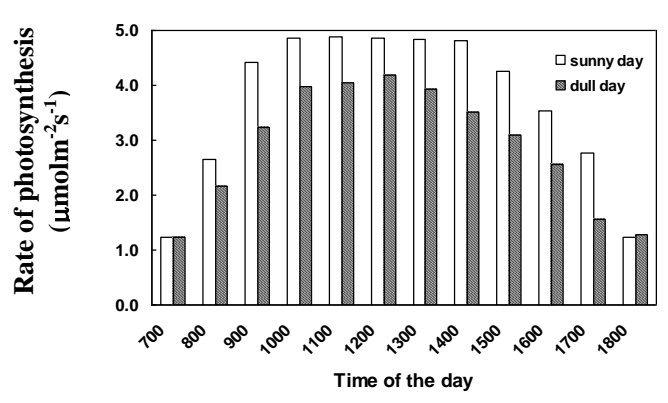

Fig. 9. Diurnal variation in the photosynthetic rates of the genotype RRIC 121

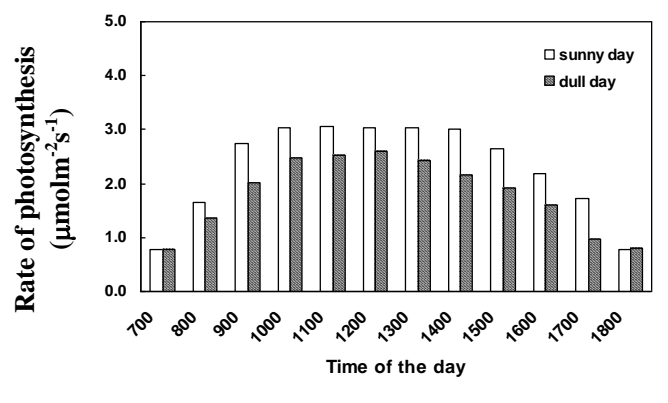

Fig. 10. Diurnal variation in the photosynthetic rates of the genotype RRIC 100 
E S Munasinghe et al.

\section{Discussion}

Present study has shown that mature rubber plantations have the potential of sequestering $c a .81 \mathrm{MT}$ of $\mathrm{CO}_{2}$ annually per hectare indicating its importance in mitigating climate change. With no vacant plants around, the tree density of 500 per hectare was used in the present density; however it is not always the case under general circumstances. According to Munasinghe (2009), tree density declines up to 285 per hectare under average growth conditions in Sri Lanka although 500 trees are planted at the beginning. Such density variation has been explained by Linear by Linear model (Munasinghe, 2009); with that and also assuming no significant change in leaf area in mature rubber plant, $\mathrm{CO}_{2}$ sequestered by one hectare of rubber lands during 24 year mature phase could be estimated as 1,296 MT. Obviously, total amount of carbon sequestered by rubber in the country should be greater than this amount if the contribution of immature rubber plantations is taken into consideration. Assuming a linear increase in $\mathrm{CO}_{2}$ sequestration over the immature phase with continuous leaf area development (up to $5^{\text {th }}$ year in growth), the total amount of carbon sequestered in rubber plantations in Sri Lanka would be 1,660 MT per hectare throughout the lifespan. With the added advantage of being an ever demanding industrial raw material and timber source, rubber could therefore be considered in any project targeting carbon sequestering. Use of rubber timber in the furniture industry warrants permanent fixing of atmospheric $\mathrm{CO}_{2}$ and minimise the pressure on natural forests for timber.

Total extent of rubber cultivation in Sri Lanka is $c a .124,300$ ha with $c a$. $77 \%$ representing mature rubber plantations (Anon, 2010). Assuming an equal distribution of these extents within respective age categories, annual $\mathrm{CO}_{2}$ sequestration in rubber plantations in Sri Lanka is $c a .10$ million MT. This highlights the importance of rubber plantations in the country in environmental aspects, particularly in combating the greenhouse effect. Although existing forestry is not eligible for carbon trading under the Clean Development Mechanism (CDM) of Kyoto protocol, a new proposal named Reduce Emission by Deforestation and forest Degradation (REDD) is on the negotiation table of United Nations Framework Convention on Climate Change (UNFCCC) to remunerate the continuous $\mathrm{CO}_{2}$ sequestration in existing forests too. If it is accepted, existing rubber plantations in Sri Lanka may also be eligible for carbon trading and so, the information generated from this study is undoubtedly useful as a readiness programme for REDD.

On average for the both clones tested, each rubber tree is capable of sequestering ca. 3.9 MT of $\mathrm{CO}_{2}$ during its mature phase. This amount refers to the amount gained through the photosynthesis. Plants do respire adding some $\mathrm{CO}_{2}$ back to the atmosphere. Based on the equation, Respiration $=\mathrm{a}$ Gross photosynthesis $+\mathrm{c}$ Total biomass 
of the tree (where a and c are constants) (De Costa, 2000), a rough estimation on the amount of $\mathrm{CO}_{2}$ evolved back to the atmosphere could be calculated as 2.1 MT per tree for the same period. Hence, net amount of $\mathrm{CO}_{2}$ fixed in the rubber tree in the end would be $c a$. 1.8 MT. However in a previous study, amount of $\mathrm{CO}_{2}$ fixed in the rubber tree has been estimated as ca. 1 MT using the overall biomass assessment (Munasinghe et al., 2008). In that particular study, no consideration has been given to the fine roots (below $1 \mathrm{~cm}$ diameter) and also periodic disposal of other tree components such as fallen twigs, fruits and cork of the bark. This justifies the difference in the values and further, there is a possibility to differ the values based on the clones used as shown in the present study.

Between the two genotypes tested, RRIC 121 was superior to RRIC 100 in sequestering atmospheric $\mathrm{CO}_{2}$. The amount of carbon fixed annually per hectare of RRIC 121 was 160\% higher than that of RRIC 100. Even in latex productivity, the genotype RRIC 121 has been proven to be better compared to the RRIC 100 (Attanayaka, 2001). Two factors responsible for the greater productivity of the RRIC 121 were identified in the present study; firstly, the high level of capacity in photosynthetic apparatus as reflected by $\mathrm{P}_{\max }$ and quantum yield in photosynthesis and secondly, improved canopy architecture enabling improved light penetration to sustain greater LAI.
In both genotypes, $\mathrm{P}_{\max }$ decreased with increase in the depth of the canopy. This situation is common to many crops and often attributed to the light environment within the canopy (Nugawela, 1989). Leaves in the top layers of the canopy operate at high light levels whilst those in the bottom experience low light levels. Quantum yield which explains the efficiency in converting light energy to chemical energy, i.e. photosynthetate, is more important to the leaves in low light environment than to the sunlit leaves to utilise available light efficiently. Therefore, a high quantum yield is advantageous to the leaves in deep strata of the canopy. However, low $\mathrm{P}_{\max }$ in lower strata is not a disadvantage as there is no sufficient light to operate at that level. In contrast, high $\mathrm{P}_{\max }$ is beneficial to leaves at the top. Therefore as a whole, the canopy is designed in a manner to maximise its photosynthetic capability.

Although the diurnal pattern of distribution was almost similar, the amount of incidence solar radiation hence photosynthetic rates are higher on sunny days than on overcast days. Further expansion of rubber cultivation in Sri Lanka has been targeted in the Intermediate zone where the annual rainfall is less than that of the Wet zone. With a reduced number of rainy days, greater sunny conditions should be experienced in the Intermediate zone resulting in a greater amount of carbon fixed when compared to the Wet zone. Also, use of high productive genotypes like RRIC 121 would harness such 
E S Munasinghe et al.

potential further. However, the reduced rainfall and the lack of soil moisture may limit such benefits in the Intermediate zone.

\section{Conclusions}

- Rubber tree is capable of sequestering $81 \mathrm{MT}$ of atmospheric $\mathrm{CO}_{2}$ per hectare annually and 1,296 MT for the whole mature phase. This information is useful in readiness for REDD.

- The genotype RRIC 121 was superior over RRIC 100 in fixing atmospheric carbon (by 160\%).

- Differences in the capacity of photosynthetic apparatus and canopy architecture were identified as the reasons for the genotypic dissimilarity in carbon sequestering.

\section{Acknowledgement}

Authors wish to thank the Climate Change Enabling Activity Phase II Project, Ministry of Environment and Natural Resources of Sri Lanka for the financial assistance and Rubber Research Institute of Sri Lanka for the facilities provided for the study.

\section{References}

Anon (1988). The National Atlas of Sri Lanka. Survey Department of Sri Lanka. $142 \mathrm{pp}$.

Anon (2001). Impacts, adaptation and vulnerability, summary for policy makers and technical summary of the Working Group II Report. Intergovernmental Panel on Climate Change, Geneva, Switzerland.
Anon (2002 a). Climate and biodiversity, IPCC technical paper V. Habiba G, Avelino S, Robert T (Eds. Watson and David Jon Dokken) Intergovernmental Panel on Climate Change, Geneva, Switzerland.

Anon (2002b). Rubber Statistical Bulletin 56 (5). International Rubber Study Group, Wembly, UK.

Anon (2010). Plantation Sector Statistical Pocket Book. Planning Unit, Ministry of Plantation Industries, Colombo. 180 pp.

Attanayaka, D P S T G (2001). Clones for commercial planting in Sri Lanka. In: Handbook of rubber. Volume 1, Agronomy. (Eds. L.M.K. Tillekeratne and A. Nugawela) Rubber Research Institute of Sri Lanka. 46-53.

De Costa, W A J M (2000). Principles of Crop Physiology: Towards an understanding of crop yield determination and improvement. Faculty of Agriculture, University of Peradeniya, $623 \mathrm{pp}$.

Ibrahim, A G (1991). Influence of rubber canopy on intercrop productivity. Trans. Malaysian Soc. Plant Physiology 2, 7579.

Iqbal, S M M (2003). Factors limiting productivity and adoption of rubber-tea intercropping in the low country wet zone of Sri Lanka. PhD Thesis, University of Essex, UK. 246 pp.

Monsi M. and Saeki T. (1953). [ The light factor in plant communities and its significance for dry matter production]. Uber den lichtfaktor in den Ptlanzengesellschaften und seine Bedentung fur die stoffproduktion. Japanese Journal of Botany 14, 22-52.

Munasinghe, E S (2009). Growth, yield, carbon fixation and economics of rubber cultivation in Sri Lanka. PhD Thesis, 
University of Sri Jayewardenepura, Sri Lanka.

Munasinghe, E S, Rodrigo, V H L, Gunawardena, U A D P and Karunatilake, P K W (2008). Quantification of growth and economically important yield components of rubber plantations in wet and intermediate zones of Sri Lanka. Proceedings of the Second Symposium on Plantation Crop Research, Sri Lanka, 299-306.

Nobel, P S and Long, S P (1985). Canopy structure and light interception. In: Techniques in Bioproductivity and Photosynthesis. (Eds. J. Coombs, D O Hall, S P Long, J M O Scurlock) Permagon Press, Oxford, 41-49 pp.

Nugawela, A (1989). Gas exchange characteristics of Hevea genotypes and their use in selection for crop yield. PhD Thesis, University of Essex, England.104 pp.
Samsuddin, $\mathrm{Z}$ and Impens, I (1979). Relationship between leaf age and some $\mathrm{CO}_{2}$ exchange characteristics of four Hevea brasiliensis Muell. Arg. clones. Photosynthetica 13(2), 208-210.

Senevirathna, A M W K, Stirling, C M and Rodrigo, V H L (2003). Growth, photosynthetic performance and shade adaptation of rubber (Hevea brasiliensis) grown in natural shade. Tree Physiology 23, 705-712.

Thornley, J H M and Johnson, I R (1990). A mathematical approach to plant and crop physiology. Oxford University Press, New York. 669 pp.

Address for correspondence: Dr E S Munasinghe, Research Assistant, Adaptive Research Unit, Rubber Research Institute of Sri Lanka, Dartonfield, Agalawatta, Sri Lanka.

E-mail: enokamunasinghe@yahoo.com 